1 Fundação Oswaldo Cruz (Fiocruz), Escola Nacional de Saúde Pública Sergio Arouca (Ensp) - Rio de Janeiro (RJ), Brasil.

lcarrilholisboa@gmail.com

\section{Características e demandas da população em situação de vulnerabilidade social acompanhadas em Belford Roxo (RJ)}

\author{
Characteristics and demands of the population in a situation of social \\ vulnerability attended in Belford Roxo (RJ)
}

Lana Carrilho Lisbôa', Vania Reis Girianelli', Luiz Carlos Fadel de Vasconcellos'

DOI: $10.1590 / 0103-1104202012512$

\begin{abstract}
RESUMO O objetivo deste estudo foi o descrever as características e demandas das famílias em acompanhamento no Centro de Referência de Assistência Social (Cras) de Santa Marta, município de Belford Roxo (RJ), no período de 2006 a 2017. Trata-se de estudo transversal descritivo com dados extraídos das fichas de acompanhamento. Um total de 87 famílias foi acompanhada no período. A maioria dos responsáveis familiares era do sexo feminino (92,0\%), menor de 40 anos (59,8\%), solteira (92,0\%) e com ensino fundamental incompleto (89,7\%). As principais demandas se referiram ao descumprimento de condicionalidade do Programa Bolsa Família (28,7\%) e evasão escolar (26,4\%). O serviço de saúde (33,3\%) apresentou o maior encaminhamento intersetorial. A mediana do tempo de acompanhamento foi de 53 meses. Não houve diferença no tempo de acompanhamento em função do grupo etário, sexo, vínculo de trabalho informal ou precário, para recebimento de benefício, forma de acesso, tipo de demanda e registro de plano de acompanhamento $(\mathrm{p} \geq 0,272)$. A demanda espontânea foi a razão de a maioria das famílias estar em acompanhamento (86,2\%), mas não havia registro sobre sua situação de vulnerabilidade. A identificação das famílias que necessitam de acompanhamento é importante para garantir acesso aos direitos socioassistenciais, além de contribuir para superar as desigualdades sociais existentes.
\end{abstract}

PALAVRAS-CHAVE Direitos humanos. Política pública. Seguridade social. Carência social. Família.

\begin{abstract}
The objective of this study was to describe the characteristics and demands of the families under follow-up at Social Assistance Referral Center (Cras) of Santa Marta, municipality of Belford Roxo, State of Rio de Janeiro, from 2006 to 2017. This is a descriptive cross-sectional study whose data were retrieved from the families' accompanying records. A total of 87 families were followed up within the study period. Most of the family heads were female (92.0\%), under 40 (59.8\%), single (92.0\%) and incomplete elementary school (89.7\%). Main demands referred to noncompliance with the Bolsa Família Program (28.7\%) and school dropout (26.4\%) conditionalities. Health service (33.3\%) showed the greatest intersectoral referral. The median following-up time was 53 months. There was no difference in the following-up time due to the age group, gender, informal or precarious employment relationship, benefit payment, access type, demand type, and follow-up plan registration $(p \geq 0,272)$. Spontaneous demand was the reason for most of the families to be under follow-up (86.2\%), although no record existed on their vulnerability situation. The identification of the families in the need to be followed is important to guarantee access to social and care rights, besides contributing to overcome the existing social inequalities.
\end{abstract}

KEYWORDS Human rights. Public policy. Social welfare. Low-income population. Family. 


\section{Introdução}

As práticas de assistência social sempre estiveram relacionadas à solidariedade e à benevolência dirigida principalmente aos pobres, doentes e deficientes. O processo de redemocratização iniciado no final da década de 1970 teve por objetivo restabelecer, além dos direitos políticos, os direitos fundamentais de grupos historicamente excluídos ${ }^{\mathbf{1}}$. Nesse contexto, a assistência social foi introduzida na Constituição para garantia de proteção social aos cidadãos, e compõe o tripé da seguridade social juntamente com a saúde e a previdência ${ }^{2}$, rompendo com a visão assistencialista e clientelista existente' ${ }^{1}$. Tal direito, contudo, apenas ganhou status de política pública e dever do Estado após a promulgação da Lei Orgânica da Assistência Social (Loas) ${ }^{3}$. A implantação da Loas, no entanto, é dificultada por aspectos políticos e econômicos, já que o Estado passa a transferir suas responsabilidades para as organizações sem fins lucrativos e para o mercado, mantendo as práticas de assistencialismo por meio de ações pontuais e fragmentadas direcionadas aos mais pobres, comprometendo a efetivação da assistência social no Brasil11. A Loas, não obstante, foi a base para estruturação do Plano Nacional de Assistência Social (PNAS) ${ }^{4}$, que se concretizou com a implantação do Sistema Único de Assistência Social (Suas), sendo o território a base para organização e consolidação do sistema ${ }^{5}$. O Suas tem sido fundamental para o combate à violência e à extrema pobreza em todo o país, proporcionando o reconhecimento da relevância da Política Pública de Proteção Social ${ }^{6}$.

Os serviços de proteção social estão organizados por níveis de baixa, média e alta complexidade. Os serviços de proteção social básica são de baixa complexidade e atuam de forma preventiva; os de proteção social especial são de média e alta complexidade e atendem indivíduos e famílias que já tiveram seus direitos violados ${ }^{7}$. Os Centros de Referência de Assistência Social (Cras) são unidades locais que têm por atribuição a organização da rede socioassistencial e a oferta de serviços de proteção social básica em determinado território. O objeto de intervenção é a família e a matricialidade sociofamiliar, uma das diretrizes estruturantes de gestão do Suas. O Cras tem como objetivo prevenir o rompimento de vínculos familiares e comunitários com ações preventivas, protetivas e proativas, ampliando o acesso dos usuários aos direitos e políticas públicas para mais de assistência social ${ }^{8}$. A intersetorialidade é um dos objetivos previsto na Loas, e prevê no seu parágrafo único que

a assistência social realiza-se de forma integrada às políticas setoriais, garantindo mínimos sociais e provimento de condições para atender contingências sociais e promovendo a universalização dos direitos sociais?.

Considerando o conceito ampliado de saúde, que se expressa por meio dos aspectos sociais, culturais, econômicos e não somente biológicos, é relevante avaliar, como estratégia de construção de cuidado integral, a parceria entre diversas secretarias. Um exemplo de intersetorialidade é o Programa Bolsa Família $(\mathrm{PBF})$, cuja transferência de renda está condicionada à manutenção da escolarização, à vacinação e ao acompanhamento em saúde das crianças e gestantes.

O Serviço de Proteção e Atendimento Integral à Família (Paif) faz parte de uma política pública e é um serviço socioassistencial ofertado de maneira exclusiva pelo Cras. Além disso, é responsável por articular os demais serviços socioassistenciais, programas de transferência de renda e benefícios assistenciais. Assim, tal serviço é destinado às famílias que estejam em situação de vulnerabilidade e necessitem de assistência social para garantia de acesso aos direitos socioassistenciais e ampliação de sua capacidade protetiva.

O Paif é um serviço que implica a construção de um plano de acompanhamento familiar juntamente com os usuários, no qual são estabelecidos os compromissos entre a família e os 
profissionais de forma a subsidiar ações para contribuir na superação dos problemas sociais vivenciados pela família. $\mathrm{O}$ atendimento pode ocorrer de forma pontual ou continuada e o propósito é fortalecer a função protetiva da família, prevenindo o rompimento de vínculos familiares e reconhecendo suas potencialidades, e colocando-a como sujeito da sua própria história. Dar suporte ao desenvolvimento das capacidades humanas pressupõe admitir a existência de indivíduos ativos e respeito à sua liberdade, o que contribui para eliminar as relações assimétricas de forma a fortalecê-los para o enfrentamento das situações de vulnerabilidade vivenciadas ${ }^{\mathbf{1 0}}$. Dessa forma, o Paif, em conjunto com outros serviços, programas e projetos, contribui para que seja garantido o acesso a direitos e serviços tanto na rede socioassistencial como nos serviços setoriais e demais políticas públicas, principalmente em relação ao acesso à saúde"1.

As famílias inseridas para acompanhamento no Paif apresentam vulnerabilidade ou risco social12. A vulnerabilidade social compreende uma condição de fragilidade dos vínculos familiares e relacionais, comprometendo a inserção e estabilidade no mercado de trabalho e o acesso aos serviços públicos e de proteção social. Já o risco, é uma consequência da não prevenção das situações de vulnerabilidade ${ }^{\mathbf{1 3}}$. Dentre os mais vulneráveis encontram-se os beneficiários do Programa Bolsa Família e do Benefício de Prestação Continuada, i.e., idosos e deficientes com renda menor que $1 / 4$ do salário-mínimo; pessoas que não possuem documentação civil básica; famílias com indivíduos reconduzidos ao convívio familiar após cumprimento de medidas protetivas ou outras situações de privação do convívio familiar e comunitário ${ }^{8}$.

No Brasil, considerando os censos de 2000 e 2010 , houve uma redução de $40,2 \%$ no percentual da população que vive pobreza extrema, percebendo até um quarto do salário mínimo, embora tal população ainda corresponda a $15,7 \%$ da população ${ }^{14}$. A pobreza extrema, embora seja determinante da maioria das situações de vulnerabilidade, não é suficiente para definir quais sujeitos necessitam de apoio ${ }^{15}$.

Apesar de o Paif existir há mais de duas décadas, ainda são raros os estudos sobre a população em acompanhamento no Cras. Este artigo tem como objetivo descrever as características e demandas das famílias em acompanhamento no Paif do Cras II Santa Marta, município de Belford Roxo - Rio de Janeiro, no período de 2006 a 2017.

\section{Material e métodos}

Trata-se de um estudo transversal descritivo das famílias incluídas para acompanhamento no Paif do Cras II Santa Marta, município de Belford Roxo (RJ).

Belford Roxo é um município da região metropolitana do estado do Rio de Janeiro, localizado na Baixada Fluminense. Está dividido em cinco distritos e contém 28 favelas, i.e, assentamentos subnormais. O município possui um dos mais elevados Produto Interno Bruto (PIB) do Estado, embora a renda per capita seja uma das mais baixas. Apresenta Índice de Desenvolvimento Humano (IDH) médio $(0,684)$, abaixo da média do Estado $(0,768)$ e do País (0,744). Em 2010, a população estimada era de 495.783 habitantes, sendo o sétimo município mais populoso do Estado. Adicionalmente, $15,7 \%$ da população vive em pobreza extrema, correspondendo à $12^{\mathrm{a}}$ pior posição do Estado ${ }^{14}$.

A rede socioassistencial do Município começou a ser implantada a partir da aprovação da PNAS-Suas, ocorrida em 2004. No ano posterior, o município contava com um Centro de Referência Especializado de Assistência Social (Creas) e seis Cras ${ }^{16}$. Atualmente, o município dispõe de treze Cras, três Creas e um Centro de Referência Especializado para População em Situação de Rua (Centro POP).

O Cras II Santa Marta, objeto deste estudo, foi inaugurado em 2005. Está localizado no terceiro distrito, que abrange quinze sub bairros 
e é responsável por cerca de oito mil famílias. Neste estudo, no entanto, foram elegíveis apenas as famílias acompanhadas no Paif do Cras II Santa Marta, município de Belford Roxo, no período de 2006 a 2017.

Os dados foram extraídos das fichas de acompanhamento do Paif do Cras II Santa Marta. Analisaram-se as variáveis relacionadas às características socioeconômicas e demográficas do responsável familiar, demandas dos usuários, atendimento no Paif e tempo de acompanhamento entre a data da inclusão e da saída.

As características socioeconômicas e demográficas consideradas dizem respeito ao sexo, idade, escolaridade, situação conjugal, renda e benefício recebido. As demandas avaliadas referem-se ao descumprimento de condicionalidade do PBF, ou seja, criança ou adolescente com frequência irregular na escola, vacinação não está em dia e não da realização da pesagem; evasão escolar; situação de abuso, exploração sexual, violência doméstica, acolhimento institucional e trabalho infanto-juvenil.

Quanto ao atendimento no Paif, foram contempladas a forma de acesso, caracterizada pela demanda espontânea e encaminhamento intra e intersetorial; e as ações realizadas, tais como inclusão no programa de acompanhamento, regularização de documentos pessoais, encaminhamentos, inserção em programas, serviços ou benefícios e visita domiciliar.

Calculou-se o percentual de cada categoria das variáveis estudadas e o tempo mediano de acompanhamento das famílias no Paif. Também foram construídas curvas de tempo de acompanhamento das famílias utilizando o método de Kaplan Meier, que é uma estimação não paramétrica do tempo de ocorrência de um evento ${ }^{17}$. As curvas de tempo foram estratificadas por grupo etário, sexo, vínculo empregatício, recebimento de benefício, forma de acesso ao Paif e descumprimento de condicionalidade do PBF. O teste Log-rank foi calculado para comparar as curvas dos estratos das variáveis, e a diferença encontrada foi considerada estatisticamente significativa quando o respectivo valor de $\mathrm{p}$ foi $\leq 0,0517$.

Os dados foram armazenados no programa Excel, versão 2013, e analisados no programa estatístico $R$ versão 3.5.118.

O estudo foi aprovado pelo Comitê de Ética em Pesquisa da Escola Nacional de Saúde Pública Sérgio Arouca (Ensp) da Fundação Oswaldo Cruz (Fiocruz) (CAAE 94184318.2.0000.5240 e parecer número 2.795.511).

\section{Resultados}

No período de 2006 a 2017, foram incluídas 91 famílias para acompanhamento no Paif do Cras Santa Marta de Belford Roxo. Destas, duas fichas de acompanhamento não foram localizadas e duas famílias realizaram apenas o primeiro atendimento. Portanto, 87 famílias foram incluídas no estudo. Houve um aumento de inclusão das famílias até 2012, com decréscimo nos anos posteriores (gráfico 1). 
Gráfico 1. Número de famílias em acompanhamento no Paif do Cras II Santa Marta em Belford Roxo (RJ), por ano de inclusão, 2006 - 2017

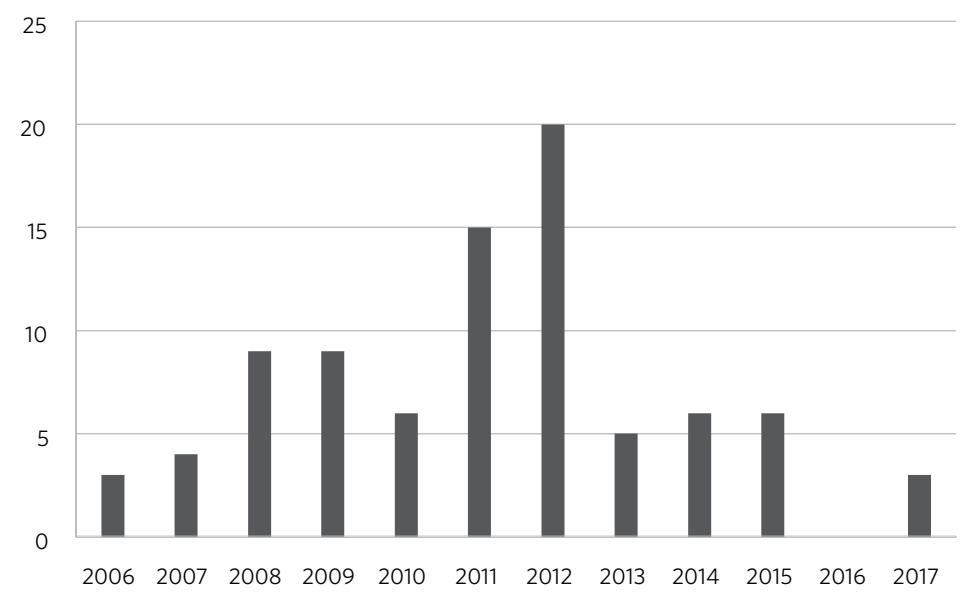

Quanto às características socioeconômicas e demográficas do responsável familiar, constatou-se que a maioria era do sexo feminino (92,0\%), grupo etário de 16 a 39 anos $(59,8 \%)$, solteira $(92,0 \%)$, baixa escolaridade, com ensino fundamental incompleto (89,7\%). Ressalta-se que dois usuários referenciados ao
Cras eram oriundos do estado de Pernambuco. Dentre os seis empregados, cinco recebiam Bolsa-Família e o outro estava com o benefício cancelado ou bloqueado. Dentre os 81 desempregados, 14 não participavam do programa de transferência de renda (17,3\%) e dois tiveram seu PBF bloqueado ou cancelado (tabela 1).

Tabela 1. Distribuição das características socioeconômicas e demográficas do responsável familiar inserido em acompanhamento no Paif no Cras II Santa Marta, Belford Roxo (RJ), 2006 a 2017

\begin{tabular}{|c|c|c|}
\hline Característica do responsável familiar & $\mathbf{N}$ & $\%$ \\
\hline \multicolumn{3}{|l|}{ Sexo } \\
\hline Masculino & 7 & 8,0 \\
\hline Feminino & 80 & 92,0 \\
\hline \multicolumn{3}{|l|}{ Grupo etário } \\
\hline Entre 16 a 39 anos & 52 & 59,8 \\
\hline Entre 40 a 59 anos & 26 & 29,9 \\
\hline 60 anos ou mais & 9 & 10,3 \\
\hline \multicolumn{3}{|l|}{ Situação Conjugal } \\
\hline Solteiro & 80 & 92,0 \\
\hline Casado & 2 & 2,3 \\
\hline Divorciado & 1 & 1,1 \\
\hline Viúvo & 1 & 1,1 \\
\hline Ignorado & 3 & 3,4 \\
\hline
\end{tabular}


Tabela 1. (cont.)

\begin{tabular}{|c|c|c|}
\hline Característica do responsável familiar & $\mathbf{N}$ & $\%$ \\
\hline \multicolumn{3}{|l|}{ Escolaridade } \\
\hline Analfabeto & 2 & 2,3 \\
\hline Fundamental Incompleto & 78 & 89,7 \\
\hline Fundamental Completo & 3 & 3,4 \\
\hline Ensino Médio Incompleto & 3 & 3,4 \\
\hline Ignorado & 1 & 1,1 \\
\hline \multicolumn{3}{|l|}{ Tipo de benefício ou programa de transferência de renda } \\
\hline Apenas Programa Bolsa Família - PBF & 63 & 72,4 \\
\hline Apenas Benefício de Prestação Continuada - BPC & 3 & 3,4 \\
\hline PBF e BPC & 4 & 4,6 \\
\hline PBF cancelado ou bloqueado & 3 & 3,4 \\
\hline Não participa de programa de transferência de renda & 14 & 16,1 \\
\hline \multicolumn{3}{|l|}{ Empregado } \\
\hline Sim & 6 & 6,9 \\
\hline Não & 81 & 93,1 \\
\hline \multicolumn{3}{|l|}{ Naturalidade } \\
\hline Rio de Janeiro & 85 & 97,7 \\
\hline Pernambuco & 2 & 2,3 \\
\hline
\end{tabular}

A demanda espontânea foi a razão de a maioria das famílias estar em acompanhamento (86,2\%) (tabela 2). As principais demandas foram o descumprimento de condicionalidade do PBF (28,7\%) e evasão escolar
(26,4\%). Destaca-se que 43 (49,4\%) famílias não tinham uma demanda específica registrada, embora se ressalte que a maioria destas (90,7\%) tenha procurado a assistência social espontaneamente.

Tabela 2. Distribuição das formas de acesso e demandas trazidas pelas famílias ao Paif de Cras II Santa Marta, Belford Roxo (RJ), 2006 a 2017

\begin{tabular}{lrr}
\hline Formas de acesso e demandas & N & $\%$ \\
\hline Formas de acesso & 75 & 86,2 \\
Demanda espontânea & 5 & 5,7 \\
Encaminhamento da rede socioassistencial & 7 & 8,0 \\
Encaminhamento intersetorial & 25 & 28,7 \\
Demandas & 23 & 26,4 \\
Descumprimento de condicionalidade & 1 & 1,1 \\
Evasão escolar & 10 & 11,5 \\
Situação de abuso ou exploração sexual & 23 \\
Situação de violência doméstica & & \\
\hline
\end{tabular}


Tabela 2. (cont.)

\begin{tabular}{lrr}
\hline Formas de acesso e demandas & N & $\%$ \\
\hline Situação de acolhimento institucional & 7 & 8,0 \\
Trabalho infanto-juvenil & 4 & 4,6 \\
Sem registro de demanda no cadastro & 43 & 49,4 \\
lgnorado & 3 & 3,4 \\
\hline
\end{tabular}

*Pode ter mais de uma demanda.

Apenas 28,7\% das famílias tinham um plano de acompanhamento registrado na ficha cadastral (tabela 3). A principal ação realizada pelos técnicos foi o encaminhamento para programas, serviços e benefícios do governo federal (97,7\%). O serviço de saúde (33,3\%) apresentou o maior encaminhamento intersetorial, seguido da habitação (11,5\%). Salienta-se que $36,8 \%$ das famílias não foi encaminhado para outros serviços da rede intersetorial.

Tabela 3. Distribuição das ações realizadas com as famílias em acompanhamento no Paif do Cras II Santa Marta, Belford Roxo (RJ), 2006 a 2017

\begin{tabular}{|c|c|c|}
\hline Acompanhamento no Paif & $\mathbf{N}$ & $\%$ \\
\hline \multicolumn{3}{|l|}{ Plano de acompanhamento } \\
\hline Sim & 25 & 28,7 \\
\hline Não registrado & 62 & 71,3 \\
\hline \multicolumn{3}{|l|}{ Encaminhamentos - Ações ${ }^{\star}$} \\
\hline Inserção em programas, serviços e benefícios do governo federal & 85 & 97,7 \\
\hline Regularização de documentos pessoais & 28 & 32,2 \\
\hline Visita Domiciliar & 41 & 47,1 \\
\hline \multicolumn{3}{|l|}{ Encaminhamento Intersetorial ${ }^{\star}$} \\
\hline Saúde & 29 & 33,3 \\
\hline Educação & 3 & 3,4 \\
\hline Justiça & 5 & 5,7 \\
\hline Creas & 3 & 3,4 \\
\hline Conselho Tutelar & 4 & 4,6 \\
\hline Secretaria de Habitação & 10 & 11,5 \\
\hline Centro Especializado de Atendimento à Mulher (Ceambel) & 2 & 2,3 \\
\hline Setor ignorado & 17 & 19,5 \\
\hline Não encaminhado para outro setor & 32 & 36,8 \\
\hline
\end{tabular}

*Pode ter mais de uma demanda. 
O tempo mediano de acompanhamento pelo programa foi de 53 meses, variando de 2 a 152 meses. As curvas dos tempos de acompanhamento no Paif dos familiares mostram que não houve diferença estatisticamente significativa no tempo de acompanhamento em função do grupo etário $(p=0,901)$, sexo $(p=0,611)$, vínculo de trabalho informal ou precário $(\mathrm{p}=$ $0,496)$, recebimento de benefício $(p=0,547)$, forma de acesso $(p=0,342)$, tipo de demanda $(\mathrm{p}=0,272)$ e registro de plano de acompanhamento no Paif $(\mathrm{p}=0,867)$ (figura 1$)$.

Figura 1. Curvas dos tempos de acompanhamento das famílias no Paif estratificadas por variáveis selecionadas, Cras II Santa Marta, Belford Roxo (RJ), 2006 a 2017

A - Grupo etário

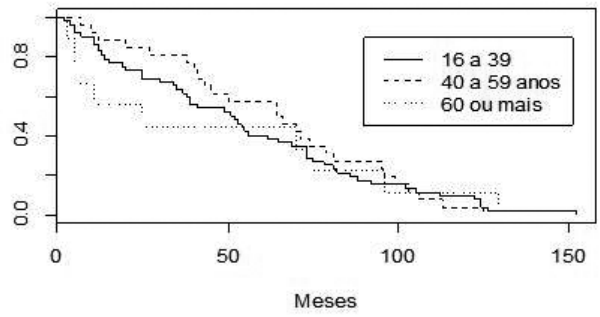

C - Empregado

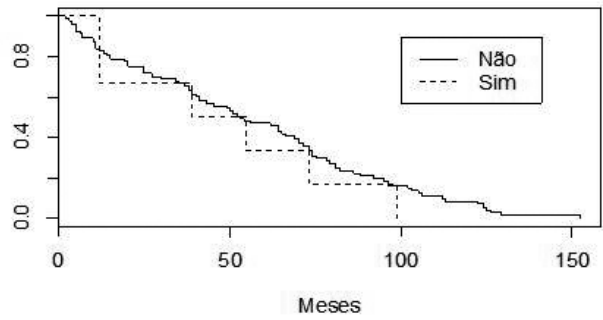

E - Forma de acesso ao Paif

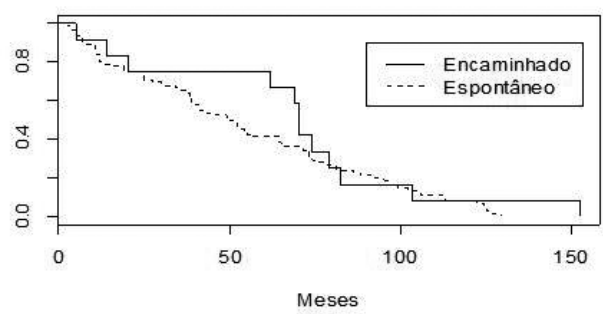

$B-\operatorname{Sexo}$

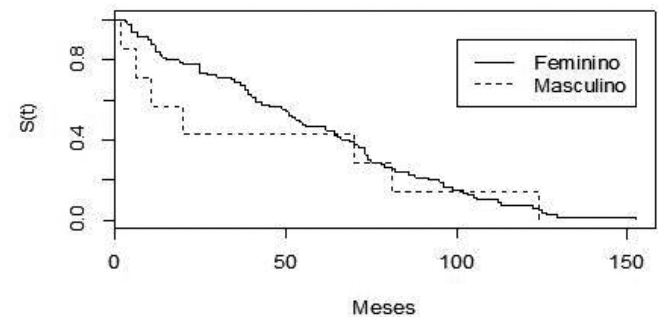

D - Recebimento de benefício

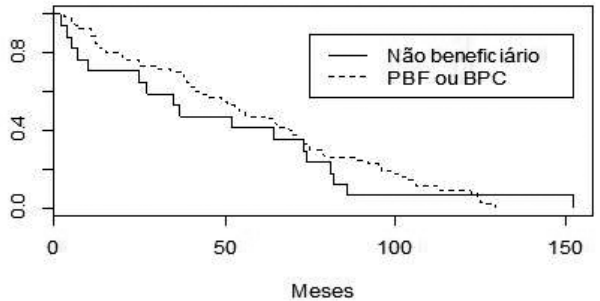

F - Descumprimento de condicionalidade do PBF

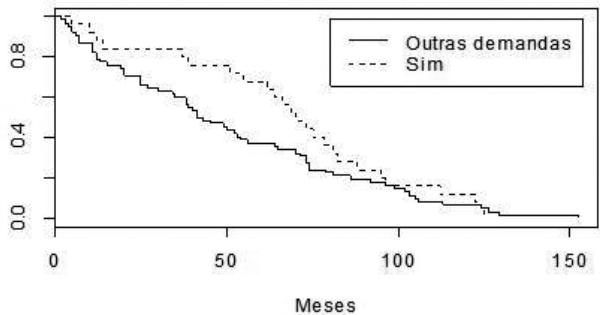

G - Registro de plano de acompanhamento no Paif

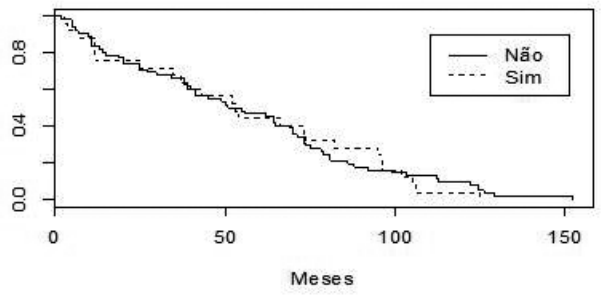




\section{Discussão}

Apenas 87 famílias ficaram em acompanhamento no Paif, inviabilizando a análise da mudança na tendência no período estudado. Embora tenha ocorrido um aumento na inclusão das famílias desde a implantação do serviço em 2005 até 2012, houve decréscimo nos anos posteriores, o que pode ser mais o reflexo de uma mudança macro política do que uma redução da demanda, tendo em vista que as condições de vida da população têm piorado com o aumento do desemprego. Segundo a Pesquisa Nacional por Amostra de Domicílios Contínua ${ }^{19}$ o percentual de desocupação superou $10 \%$ a partir de 2016 , alcançando $12,7 \%$ no primeiro trimestre de 2019 , crescendo o aumento das iniquidades sociais, principalmente para grupos populacionais em situação de maior vulnerabilidade. Some-se a isso a implementação das políticas de austeridade, que vem trazendo efeitos nefastos sobre o financiamento das políticas sociais no Brasil e resultando na precarização dos serviços e da política de saúde, por exemplo.

Em 2016, ano com nenhuma família incluída, o contexto foi de intensificação das ações neoliberais, visando à redução dos gastos públicos ${ }^{20}$. Os programas e serviços relacionados à pasta da assistência social tendem a ser os mais afetados por não haver um percentual mínimo da arrecadação pactuado em cada esfera de governo em razão da vinculação obrigatória, como ocorre com a saúde e a educação.

Um serviço ou uma política pública por si só, contudo, não é suficiente para responder às demandas da população, em particular a mais vulnerável. Ademais, a melhoria da saúde de uma determinada população pode depender mais de investimento de outra política setorial, como, por exemplo, o saneamento básico, do que do aumento no investimento dos gastos tradicionais relacionados à saúde.

A intersetorialidade é uma estratégia de construção do cuidado integral, mas ainda se verifica na prática profissional uma necessidade de ampliação do debate acerca da rede intra e intersetorial, bem como da articulação entre elas. Tal limitação compromete o enfrentamento da determinação social que incide no processo saúde-doença.

A assistência social se insere numa realidade complexa, que, por vezes, encontra limites para atuação profissional. Tal contexto provoca o profissional a refletir sobre a sua prática e reconhecer que a realidade é dinâmica, com avanços e retrocessos na relação entre o Estado e a sociedade.

Viu-se que, das famílias em acompanhamento, a maioria tinha a mulher como responsável (92\%). Embora a família seja o foco da atenção, como previsto nos marcos legais da Política de Assistência - PNAS4 e nos marcos normativos do Suas - Norma Operacional Básica (NOB)/Suas ${ }^{5}$, há a priorização das mulheres como responsável pelo cadastro único. Esse cadastro é um instrumento de identificação e caracterização socioeconômica das famílias de baixa renda a ser obrigatoriamente utilizado para seleção de beneficiários e integração de programas sociais do governo federal. Posteriormente, torna-se o público preferencial do programa de transferência da renda - PBF, que reforça a responsabilização feminina por meio das condicionalidades, compromissos assumidos pela família nas áreas da educação e da saúde e que precisam ser cumpridos para manutenção do benefício.

Outro achado relevante a ser destacado é que 17,3\% dos responsáveis familiares em situação de desemprego não participou de nenhum programa de transferência de renda. Tal fato reflete as implicações da gestão neoliberal no campo das políticas sociais, trazendo impactos em nível do trabalho e também implicações psicossociais e tornando relevante articular as intervenções tanto na assistência social como em outras políticas públicas, como as de saúde e saúde mental21.

O fato de a maioria das famílias ter sido incluída para acompanhamento familiar no Paif por demanda espontânea (86,2\%), reforça que o Cras é a principal porta de entrada para o acesso às políticas públicas, embora os registros não contivessem a situação de 
vulnerabilidade que elegia as famílias a tal inclusão. Adicionalmente, a maioria das famílias (71,2\%) não tinha um plano de acompanhamento registrado, embora tenham sido acompanhadas por dois a 153 meses. Ademais, se destacam as formas diferenciadas de registros das informações nas fichas do Paif, o que impossibilita sistematizar a prática e definir indicadores sobre o acompanhamento.

É importante salientar que, no atual contexto de ofensivas conservadoras aos direitos sociais, há um processo de desmonte dos equipamentos públicos, acrescido de um financiamento inadequado, tornando inviável a prestação de serviços com qualidade, o que pode desencadear o fim do Suas. Somandose a esse corte de recursos em relação aos serviços socioassistenciais, ocorrem outras formas de precarização do trabalho tais como a desvalorização dos trabalhadores do Suas, baixa remuneração, condições precárias de trabalho, a não preservação a saúde do trabalhador e os riscos e exposição à violência urbana nos territórios.

Ademais, segundo o último Censo Suas, publicado $2016^{22}$, observa-se que, desde 2010, mais da metade dos profissionais das Secretarias Municipais de Assistência Social é comissionada ou sem vínculos trabalhistas. Tal situação favorece a alta rotatividade desses profissionais, relacionada à descontinuidade político-partidária, o que prejudica a continuidade das ações e o estabelecimento de vínculos entre esses profissionais e os usuários, impactando diretamente o atendimento prestado.

\section{Considerações finais}

O Paif já existia no estado do Rio de Janeiro desde 1999 com o objetivo de ordenar e organizar a assistência social de maneira sistêmica; mas perdeu sua razão de existir, pois a proposta foi incorporada ao Suas na sua implantação em 2005. O serviço Paif foi mantido, mas tentaram convertê-lo numa metodologia de acompanhamento sociofamiliar.
O fato de haver repasse do governo federal tem estimulado a implantação desses serviços nos municípios, embora geralmente em condições precárias, sem recursos humanos suficientes para atender à demanda, dificultando a operacionalização e a execução da política de assistência social. As recomendações do Paif não contemplam a realidade e desconsideram a complexidade das refrações da questão social. Tal situação superestima a capacidade do profissional em responder às demandas das famílias, que, por não serem atendidas, frustram o profissional. Em contrapartida, a sociedade acaba, muitas vezes, atribuindo a culpa às famílias pelo fracasso, reforçando e transferindo a responsabilidade dos cuidados e da proteção social para as famílias. As necessidades sociais são tratadas como problemas privados, de "forma despolitizada, quando na verdade se trata de questões de ordem pública, afetas à sociedade e, em particular, ao Estado"23(136).

O direito à saúde é universal. Portanto, não é condição passar pelo serviço da assistência social para ter acesso a esse direito. A política de assistência social é importante para democratizar as informações quanto aos direitos da população, em particular para os indivíduos em situação de vulnerabilidade. É importante trazer este debate sobre a assistência social como uma articuladora das demais políticas e como ela pode contribuir para a viabilização do acesso ao direito à saúde e à dignidade humana.

O trabalho intersetorial é fundamental para viabilizar o processo de referência e contra referência a serviços socioassistenciais e a serviços de outras políticas setoriais, assegurando a interdisciplinaridade, a qualidade dos serviços e ação em rede. Ademais contribui para monitorar a resolutividade das ações e proporcionar maior transversalidade da assistência social com as demais políticas públicas, em especial a saúde, educação, habitação, sistema sociojurídico, trabalho e renda. Assim, a intersetorialidade é essencial no que diz respeito à garantia de direitos e das políticas sociais, 
e se torna necessária, porque a população apresenta demandas variadas e complexas.

Defender a oferta de serviços de qualidade no Suas implica a garantia de condições de trabalho pautadas nos princípios ético- políticos dos trabalhadores do Suas e na defesa dos direitos socioassistenciais dos usuários, estimulando sua participação nos espaços de controle social, como conselhos, fóruns e conferências. Ademais, a capacitação dos profissionais e a estruturação das condições de trabalho são fundamentais. Nesse sentido, a busca pela defesa e a ampliação da proteção social e dos direitos sociais na perspectiva do conceito de seguridade social ampliada visa a reduzir as vulnerabilidades e possibilitar aos cidadãos o acesso às políticas setoriais e serviços públicos, opondo-se à violação de prerrogativas profissionais e dos direitos humanos.

A adequada inclusão no acompanhamento Paif é importante, pois garante a aplicação de recursos para a população que realmente necessita de proteção social, proporcionando acesso às informações, aos bens, aos serviços, aos direitos socioassistenciais e às demais políticas setoriais e de defesa de direitos. Esse serviço dá visibilidade ao público que recorre à política de assistência, desnaturalizando a pobreza e as desigualdades que extrapolam as considerações econômicas.

Espera-se que o estudo contribua para o aperfeiçoamento da equipe para um melhor atendimento da população mais vulnerável pelo serviço, e consequentemente, amplie a visibilidade do trabalho realizado e a proteção social dessa população para que seja garantido o acesso à cidadania.

\section{Colaboradores}

Lisbôa LC (0000-0002-5669-481X)* contribuiu para elaboração do trabalho, análise e interpretação dos dados, redação da primeira versão e aprovação da versão final do manuscrito. Girianelli VR (0000-0002-8690-9893)* contribuiu para a concepção do estudo, análise e interpretação dos dados, revisão crítica do conteúdo e aprovação da versão final do manuscrito. Vasconcellos LCF (0000-0002-76799870)* contribuiu para análise e interpretação dos dados, revisão crítica do conteúdo e aprovação da versão final do manuscrito.
*Orcid (Open Researcher and Contributor ID).

\section{Referências}

1. Lonardoni E, Gimenes JG, Santos ML, et al. O processo de afirmação da assistência social como política social. Serviço Social em Revista. 2006 [acesso em 2020 maio 7]; 8(2). Disponível em: http://www. uel.br/revistas/ssrevista/c-v8n2_sonia.htm.

2. Brasil. Constituição da República Federativa do Brasil. Capítulo II da Seguridade Social. 1988 [acesso em 2018 jun 14]. Disponível em: https://www2.camara.
leg.br/atividadelegislativa/legislacao/Constituicoes_ Brasileiras/constituicao1988.html/arquivos/Constituiode1988.pdf.

3. Brasil. Lei no 8.742, de 7 de dezembro de 1993. Dispõe sobre a organização da Assistência Social e dá outras providências. Diário Oficial da União. 8 Dez 1993. [acesso em 2020 maio 7]. Disponível em: http:// www.planalto.gov.br/ccivil_03/leis/18742.htm. 
4. Brasil. Ministério do Desenvolvimento Social e Combate à Fome. Política Nacional de Assistência Social (PNAS). Brasília, DF: Ministério do Desenvolvimento Social e Combate à Fome; 2004.

5. Brasil. Ministério do Desenvolvimento Social e Combate à Fome. Norma Operacional Básica da Assistência Social - NOB/SUAS. Brasília, DF: Ministério do Desenvolvimento Social e Combate à Fome; 2005.

6. Schmidt JAC, Silva MM. A assistência Social na contemporaneidade: uma análise a partir do orçamento público. Katálysis. 2015; 18(1):86-94.

7. Brasil. Ministério do Desenvolvimento Social e Combate à Fome. Tipificação Nacional de Serviços Socioassistenciais. Brasília, DF: Ministério do Desenvolvimento Social e Combate à Fome; 2009.

8. Brasil. Ministério do Desenvolvimento Social e Combate à Fome. Orientações técnicas: Centro de Referência de Assistência Social (CRAS). Brasília, DF: Ministério do Desenvolvimento Social e Combate à Fome; 2009.

9. Brasil. Lei ${ }^{\circ} 12.43$, de 6 de julho de 2011. Altera a Lei $\mathrm{n}^{\circ}$ 8.742, de 7 de dezembro de 1993, que dispõe sobre a organização da Assistência Social. Diário Oficial da União. 7 Jul 2011. [acesso em 2020 maio 7]. Disponível em: http://www.planalto.gov.br/ccivil_03/_Ato20112014/2011/Lei/L12435.htm.

10. Bronzo C. Vulnerabilidade, empoderamento e metodologias centradas na família: conexões e uma experiência para reflexão. In: Sposati A, organizador. Concepção e gestão da proteção social não contributiva no Brasil. Brasília, DF: Ministério do Desenvolvimento Social e Combate à Fome; Organização das Nações Unidas para a Educação, a Ciência e a Cultura; 2009. p. 171-201.

11. Brasil. Ministério do Desenvolvimento Social e Combate à Fome. Orientações Técnicas sobre o Serviço de Proteção e Atendimento Integral à Família Brasília, DF: Ministério do Desenvolvimento Social e Combate à Fome; 2012. (V. 2).
12. Brasil. Ministério do Desenvolvimento Social e Combate à Fome. Orientações Técnicas sobre o Serviço de Proteção e Atendimento Integral à Família. Brasília, DF: Ministério do Desenvolvimento Social e Combate à Fome; 2012. (V. 1).

13. Fernandes RM, Hellmann A, organizadores. Dicionário crítico: política de assistência social no Brasil. Porto Alegre: UFRGS; 2016.

14. Instituto Brasileiro de Geografia Estatística [internet]. Belford Roxo. 2018 [acesso em 2018 jun 14]. Disponível em: https://www.ibge.gov.br/estatisticas-novoportal/por-cidade-estado-estatisticas. html?t=destaques\&c=3304904.

15. Castel R. A dinâmica dos processos de marginalização: da vulnerabilidade a “desfiliação”. Caderno CRH. 1997; 26/27:19-40.

16. Anselmo G. A construção da rede socioassistencial do município de Belford Roxo na perspectiva do PNAS/ SUAS: limites e possibilidades [dissertação]. Rio de Janeiro: Pontifícia Universidade Católica do Rio de Janeiro; 2008. 120 p.

17. Carvalho MS, Andreozzi VL, Codeço CT. Estimação não paramétrica. In Análise de Sobrevida: teoria e aplicações em saúde. Rio de Janeiro: Fiocruz; 2005.

18. R Core Team. R: A language and environment for statistical computing [internet]. Vienna, Austria: R Foundation for Statistical Computing; 2018. [acesso em 2018 out 30]. Disponível em: http://www.R-project.org.

19. Instituto Brasileiro de Geografia Estatística. Pesquisa Nacional por Amostra de Domicílios Contínua (PNAD) [internet]. 2019. [acesso em 2019 maio 14]. Disponível em: https://www.ibge.gov.br/estatisticas/sociais/trabalho/9171-pesquisa-nacional-por-amostra-de-domicilios-continua-mensal. html?=\&t=destaques.

20. Brasil. Emenda Constitucional no 95 , de 15 de dezembro de 2016. Altera o Ato das Disposições Constitucionais Transitórias, para instituir o Novo Regi- 
me Fiscal, e dá outras providências. Diário Oficial da União. 16 Dez 2016. [acesso em 2020 maio 7]. Disponível em: http://www.planalto.gov.br/ccivil_03/constituicao/emendas/emc/emc95.htm.

21. Vasconcelos EM, Morgado R. Proposta Conceitual do PAIF: subsídios analíticos e metodológicos na lógica do Sistema Único da Assistência Social - SUAS e do Programa de Atendimento Integral à Família PAIF - RJ. Rio de Janeiro: Governo do Estado do Rio de Janeiro; 2005.

22. Brasil. Ministério do Desenvolvimento Social e Combate à Fome. Censo SUAS 2016: análise dos compo- nentes sistêmicos da política nacional de assistência social. Brasília, DF: Ministério do Desenvolvimento Social e Combate à Fome; 2016.

23. Alencar MMT. Família, trabalho e reprodução social: limites na realidade brasileira. In: Alencar MMT, Duarte MJO, organizadores. Família e Famílias: práticas sociais e conversações contemporâneas. 2. ed. Rio de Janeiro: Lumen Juris; 2012.

Recebido em 28/06/2019 Aprovado em 08/04/2020

Conflito de interesses: inexistente

Suporte financeiro: não houve 